\title{
ANÁLISE DA INSTITUCIONALIZAÇÃO DA MEDIAÇÃO A PARTIR DAS INOVAÇÕES DO NOVO CÓDIGO DE PROCESSO CIVIL (NCPC) E DA LEI N 13.140/2015 (LEI DA MEDIAÇÃO)
}

\section{ANALYSIS OF MEDIATION INSTITUTIONALIZATION INNOVATIONS IN FRONT OF THE NEW CODE OF CIVIL PROCEDURE (NCPC) AND LAW No. 13.140/2015 (MEDIATION LAW)}

\begin{abstract}
SERGIO RodRIGO MARTINEZ
Doutor em Direito das Relações Sociais pela UFPR. Professor Associado do Curso de Direito da Universidade Estadual do Oeste do Paraná (UNIOESTE). Cascavel, PR, Brasil. selfpeq@yahoo.com

STHEPHANIE GALHARDO SCHULZ Advogada. Bacharel em Direito pela da Universidade Estadual do Oeste do Paraná (UNIOESTE). Cascavel, PR, Brasil. sthephanie_16@hotmai.com
\end{abstract}

\section{RESUMO}

O presente estudo destaca as inovações na seara da Mediação presentes no novo Código de Processo Civil e na Lei 13.140/2015. A prática mediativa é uma alternativa às formas jurisdicionais de resolução de conflitos, porque busca a construção do consenso, ao estimular o diálogo e melhorar a comunicação entre as pessoas. As novas normas jurídicas brasileiras trazem a tentativa de institucionalização da mediação, o que pode não trazer os benefícios esperados em termos de efetividade na resolução de controvérsias. Nesse sentido, o estudo analisa os pontos positivos e negativos da institucionalização prevista. Essa temática foi desenvolvida por meio de pesquisa teórica e dedutiva, ao revisar dados em leis e doutrinas sobre o tema.

Palavras-chave: Institucionalização; Lei da Mediação; Mediação; Novo Código de Processo Civil.

\begin{abstract}
This study highlights the innovations in the harvest of mediation presented in the new Code of Civil Procedure and Brazilian Law 13.140/2015. Mediation is an alternative to the judicial forms of conflict resolution, because it seeks to build consensus, promoting dialogue and improving communication between people. The new Brazilian legal rules bring the attempt to institutionalize mediation, which may not bring the expected benefits in terms of effectiveness in the resolution of disputes. In this sense, the study analyzes the strengths and weaknesses of the proposed institutionalization. This theme was developed through theoretical and deductive research, by reviewing data on laws and literature on the subject.
\end{abstract}

Keywords: Institutionalization; Mediation Law; Mediation; New Code of Civil Procedure. 


\section{SUMÁRIO}

INTRODUÇÃO; 1 REVISÃO DE DADOS; CONCLUSÃO; REFERÊNCIAS.

\section{INTRODUÇÃO}

A mediação destaca-se como contraponto às formas jurisdicionais de resolução de conflitos, concebida de modo a primar pela construção e facilitação do diálogo na pacificação social e, assim, fora concebida como um meio alternativo do acesso à Justiça, a serviço da autonomia dos indivíduos em autogerirem suas controvérsias. As ações judiciais, comumente longas e custosas e dependentes de uma gigantesca máquina do Estado, impõem decisões binárias no sentido ganha ou perde. Isso se afasta totalmente do contexto mediativo, pois o que se busca, na maior parte dos casos é o ganha/ganha, a ser construído a partir do diálogo, até se chegar a um acordo satisfatório, capaz de encerrar satisfatoriamente a controvérsia.

O que se vê na leitura do novo Código de Processo Civil e na nova Lei da Mediação (13.140/2015) é uma tentativa de institucionalização da mediação dentro da estrutura do Estado. Por um lado, isso reconhece a importância negocial da mediação na resolução das controvérsias e procura trazer segurança jurídica ao incentivar a ampliação de seu uso, o que já acontece em vários países. Por outro lado, isso confronta a égide negocial e autônoma da mediação o que, por hipótese, poderia "burocratizar" o instituto e demandar a criação de mais estrutura estatal, além de agravar despesas a agravar os gastos públicos com o acesso à Justiça.

Nesse contexto, o presente trabalho aborda a recente regulamentação da mediação, ocorrida com a publicação do novo Código de Processo Civil (NCPC), Lei $n^{\circ} 13.105$, de 16 de março de 2015, e da Lei 13.140 de 2015 (Lei da Mediação), de 26 de junho de 2015, a fim de se questionar se a institucionalização da mediação, conforme está inserida nessas novas normas jurídicas, trará mais benefícios ou prejuízos no uso efetivo deste instituto para fins de pacificação social.

Para tanto, com base na pesquisa teórica dedutiva, materializada por meio de uma revisão de dados bibliográficos, primeiramente é feita uma localização histórica, para logo em seguida se passar à análise dos novos postulados legais trazidos, dentro de uma interpretação axiológica. Serão analisados os benefícios e prejuízos possíveis na implementação e institucionalização da mediação, não mais enquanto meio alternativo de resolução de controvérsias, mas agora enquanto instrumento de Jurisdição do Estado. 


\section{REVISÃO DE DADOS}

Cumpre enfatizar que, embora a discussão acerca da mediação no Brasil seja contemporânea, o instituto tem origens remotas. A mediação origina-se nas sociedades antigas. A finalidade primordial dessa via conciliativa era manter a coesão e pacificação social nas comunidades. Há indícios de que o instituto já era amplamente utilizado na sociedade chinesa, bem como na Grécia Antiga, Egito e Babilônia como forma de manutenção da harmonia entre os integrantes da comunidade e, consequentemente, de minorar conflitos sociais. ${ }^{1}$

O marco ocidental e contemporâneo da mediação, por sua vez, data da década de 1970, nos Estados Unidos da América, período em que houve efetiva institucionalização dessa via alternativa de resolução de conflitos dentro do próprio aparato legal do Estado. Na Califórnia, inclusive, a Mediação fora instituída como instância obrigatória antes da judicial, por conta dos bons resultados que apresentou enquanto era utilizada na esfera privada. ${ }^{2}$

Posteriormente à regulamentação americana, a Inglaterra passou a prever no ordenamento seu próprio sistema de mediação, por meio de um pequeno grupo de advogados que formularam uma campanha voltada para o fomento dos métodos alternativos de conflitos. Assim como ocorrido no sistema americano, a via mediativa alcançou lugar dentro do sistema legal após crescer no âmbito privado britânico. ${ }^{3}$

No Oriente, a República Popular da China possui lei específica para tratar acerca da Mediação Popular, promulgada em 2010, em vigor desde então. No artigo $1^{\circ}$ da referida lei consta como objetivo a resolução de conflitos de forma célere, a fim de manter a "harmonia social". ${ }^{4}$ Por seu turno, a França experimentou situação diferenciada, porque a mediação iniciouse no âmbito do direito público e se expandiu para o privado, tendo sido efetivamente positivada

\footnotetext{
${ }^{1}$ SPENGLER, Fabiana Marion; SPENGLER NETO, Theobaldo. Mediação enquanto política pública: a teoria, a prática e o projeto de lei. Santa Cruz do Sul, Edunisc, 2010. Disponível em: <http://www.unisc.br/portal/pt/editora/e-books/95/mediacao-enquanto-politica-publica-a-teoria-apratica-e-o-projeto-de-lei-.html>. Acesso em: 30 jul. 2015. p. 18.

2 LUCHIARI, Valéria Ferioli. Mediação judicial: análise da realidade brasileira origem e evolução até a Resolução n. 125, do Conselho Nacional de Justiça. In: GRINOVER, Ada Pellegrini; WATANABE, Kazuo (Coord.). Rio de Janeiro: Forense, 2012. (Coleção ADRS), p. 19.

${ }^{3}$ LUCHIARI, Valéria Ferioli. Mediação judicial: análise da realidade brasileira origem e evolução até a Resolução n. 125, do Conselho Nacional de Justiça. In: GRINOVER, Ada Pellegrini; WATANABE, Kazuo (Coord.). Rio de Janeiro: Forense, 2012. (Coleção ADRS), p. 19.

${ }^{4}$ PIQUET, Hélène. A mediação popular na China: acesso à justiça ou harmonia imposta? Revista Meritum. Belo Horizonte. Vol. 7. 2012, p. 157-167.
} 
ANÁLISE DA INSTITUCIONALIZAÇÃO DA MEDIAÇÃO A PARTIR DAS INOVAÇÕES DO NOVO CÓDIGO DE PROCESSO CIVIL (NCPC) E DA LEI N 13.140/2015 (LEI DA MEDIAÇÃO)

SERGIO RODRIGO MARTINEZ STEPHANIE GALHARDo SCHULZ

no ordenamento francês em $1990 .^{5} \mathrm{Na}$ América Latina, a Argentina fora pioneira ao editar em 1992 o Decreto $n^{\circ}$ 1480/1992, cujo teor declarava ser de interesse nacional a institucionalização da mediação. Em 05 de outubro de 1994, fora sancionada a Lei $n^{\circ} 24.573$, a qual passou a tornar a mediação via obrigatória para casos patrimoniais. ${ }^{6}$

Para o mediador americano Jeffrey Krivis, professor adjunto do Instituto Strauss para Resolução de Conflitos, "a medida que o século avança, os advogados são testemunhas de um casamento único, cuja base é o enlace entre o sistema privado não-adversarial da mediação e o sistema público adversarial de Justiça."

Cabe destacar que, no tocante à resolução de controvérsias, o Brasil caracteriza-se por ter um modelo jurisdicional clássico, que busca soluções predominantemente por meio do processo judicial. Só marginalmente a essa forma de dirimir controvérsias, houve até agora tentativas de implementar métodos alternativos de resolução de conflitos dentro do ordenamento jurídico brasileiro, que sejam mais céleres e eficazes e que representem avanços na construção da Cultura da Paz. ${ }^{8}$

Uma das recentes tentativas fora a elaboração da Resolução $\mathrm{n}^{\circ} 125$ do Conselho Nacional de Justiça (CNJ), publicada em $1^{\circ}$ de dezembro de 2010, a qual dispõe acerca da Política Judiciária Nacional de Tratamento Adequado de Conflitos de Interesses e que, posteriormente, influenciou a redação de dispositivos presentes no NCPC, bem como na Lei 13.140/2015. ${ }^{9}$

O NCPC, já no parágrafo terceiro do artigo $1^{\circ}$, preconiza o dever de todos os operadores do Direito de estimular métodos alternativos de resolução de conflitos. 0 dispositivo transparece

\footnotetext{
${ }^{5}$ LUCHIARI, Valéria Ferioli. Mediação judicial: análise da realidade brasileira origem e evolução até a Resolução n. 125, do Conselho Nacional de Justiça. In: GRINOVER, Ada Pellegrini; WATANABE, Kazuo (Coord.). Rio de Janeiro: Forense, 2012. (Coleção ADRS), p. 19.

${ }^{6}$ LUCHIARI, Valéria Ferioli. Mediação judicial: análise da realidade brasileira origem e evolução até a Resolução n. 125, do Conselho Nacional de Justiça. In: GRINOVER, Ada Pellegrini; WATANABE, Kazuo (Coord.). Rio de Janeiro: Forense, 2012. (Coleção ADRS), p. 19.

${ }^{7}$ No original: "As we turn the century clock ahead, lawyers stand witness to a unique marriage, one in which the knot has been tied between the private non-adversarial system of mediation and the public, adversarial process known as the Civil Justice System." In: KRIVIS, Jeffrey. End of the Cold War: The Marriage of Mediation and the Court System. Disponivel em: <http://mediate.com/articles/krivis7.cfm\#bio> Acesso em: 02 out. 2015.

${ }^{8}$ WATANABE, Kazuo. Modalidade de mediação. In: Mediação: Um Projeto Inovador. José Delgado et. al. Série Cadernos do Conselho da Justiça Federal. Brasília: Centro de Estudos Judiciários, 2003. v. 22. Disponível em: <http://daleth.cjf.jus.br/revista/seriecadernos/vol22/artigo04.pdf>. Acesso em: 30 jul. 2015, p. 46.

9 LUCHIARI, Valéria Ferioli. Mediação judicial: análise da realidade brasileira origem e evolução até a Resolução n. 125, do Conselho Nacional de Justiça. In: GRINOVER, Ada Pellegrini; WATANABE, Kazuo (Coord.). Rio de Janeiro: Forense, 2012. (Coleção ADRS), p. 81.
} 
ANÁLISE DA INSTITUCIONALIZAÇÃO DA MEDIAÇÃO A PARTIR DAS INOVAÇÕES DO NOVO CÓDIGO DE PROCESSO CIVIL (NCPC) E DA LEI No 13.140/2015 (LEI DA MEDIAÇÃO)

SERGIO RODRIGO MARTINEZ STEPHANIE GALHARDO SCHULZ

a preocupação legislativa, já contida na Resolução $n^{\circ} 125$ do $\mathrm{CNJ}$, em estimular uma mudança positiva de mentalidade aos operadores do Direito, para o melhor uso da mediação na solução das controvérsias.

Lagrasta Neto ${ }^{10}$ cita o dever de todos os agentes jurídicos incentivarem a mediação, tais como magistrados, advogados, membros do Ministério Público e serventuários da justiça. Entretanto, na visão do autor, não basta se incentivar o uso da mediação e a elaboração de dispositivos legais, e sim, fazer-se uma mudança na estratégia da utilização dessa via consensual, para efetivar sua inserção na realidade brasileira. Para isso, o instituto deveria ser imposto previamente às partes que desejarem acesso ao juízo.

0 principal receio quanto à utilização imposta da mediação, mesmo sem o assentimento e conscientização das partes ao uso desse método, é torná-lo algo inócuo e meramente formal a ser cumprido previamente no processo, como foi a adoção da audiência de conciliação, no Código de Processo Civil anterior:

A compulsoriedade da mediação e o estreitamento de seus laços ao processo civil pode gerar a busca pela eficiência quantitativa do processamento de casos, redundando num tratamento mais hierarquizado, menos leigo e mais profissional, menos flexível e mais formalista do instituto. Com isso, muitos dos aspectos que caracterizam a mediação acabam cedendo lugar a valores que atendem mais ao sistema judicial do que aos próprios usuários do processo de resolução de disputas $^{11}$.

Felizmente a obrigatoriedade da mediação prévia ao processo foi evitada, assim como foi garantida, pela redação do parágrafo quarto do artigo 1966 do NCPC ${ }^{12}$, a liberdade procedimental e a autonomia no uso da mediação, salvo nos casos de direito de família, onde seu uso vai além dos interesse disponíveis das partes. Nesse sentido, a liberdade procedimental e autonomia representam aspectos positivos condizentes com os princípios inerentes ao instituto

${ }^{10}$ LAGRASTA NETO, Caetano. Mediação, conciliação e suas aplicações pelo Tribunal de Justiça de São Paulo. In: GRINOVER, Ada Pellegrini; WATANABE, Kazuo. (Coords.) Mediação e gerenciamento do processo: revolução na prestação jurisdicional: guia prático para a instalação do setor de conciliação e mediação. São Paulo: Ed. Atlas, 2007, p. 11.

11 BARBADO, Michelle Tonon (Org.). Reflexões sobre a institucionalização da mediação no direito positivo brasileiro. Disponível em: <http://www.arcos.org.br/livros/estudos-de-arbitragem-mediacao-enegociacao-vol3/parte-ii-doutrina-parte-especial/reflexoes-sobre-a-institucionalizacao-da-mediacao-nodireito-positivo-brasileiro/>. Acesso em: 01 nov. 2015.

12 Art. 166. A conciliação e a mediação são informadas pelos princípios da independência, da imparcialidade, da autonomia da vontade, da confidencialidade, da oralidade, da informalidade e da decisão informada. § $4^{\circ} \mathrm{A}$ mediação e a conciliação serão regidas conforme a livre autonomia dos interessados, inclusive no que diz respeito à definição das regras procedimentais. In: BRASIL. Lei $n^{\circ}$ 13.105, de 16 de março de 2015. Código de Processo Civil. Brasília, Disponível em: <http://www.planalto.gov.br/ccivil_03/_Ato2015-2018/2015/Lei/L13105.htm>. Acesso em: 20 jun. 2015. 
ANÁLISE DA INSTITUCIONALIZAÇÃO DA MEDIAÇÃO A PARTIR DAS INOVAÇÕES DO NOVO CÓDIGO DE PROCESSO CIVIL (NCPC) E DA LEI No 13.140/2015 (LEI DA MEDIAÇÃO)

SERGIO RODRIGO MARTINEZ STEPHANIE GALHARDO SCHULZ

tradicional da mediação, tais como o da independência, da imparcialidade, da normalização do conflito, da autonomia da vontade, da confidencialidade, da oralidade, da informalidade e da decisão informada, reconhecidos pelo "caput" do artigo 166, do NCPC. ${ }^{13}$ Nesse aspecto, caminhou satisfatoriamente o NCPC.

Outra inovação trazida pelo NCPC diz respeito à determinação que os tribunais criem Centros Judiciários de Solução Consensual de Conflitos (CJSCC), conforme diploma legal contido no seu artigo $165 .^{14}$ Seria incabível a realização da audiência de mediação pelo próprio Juiz da causa e preferível que o procedimento se desse dentro dos CJSC. ${ }^{15}$

Porém, aqui vem o primeiro dado questionável da institucionalização da proposta da mediação - a criação de mais estrutura física a cargo do Estado. Ainda, cumpre destacar que, conforme disposição do NCPC, os mediadores receberão remuneração pelos serviços prestados, a ser fixada pelo tribunal competente, previsão expressa no artigo 169 do novo códex. ${ }^{16}$ Por que não se aproveitar a estrutura já existente nas serventias e assim realizar a mediação em horários normais das audiências, por mediadores voluntários, formados aos moldes dos antigos juízes de paz?

O que se discute é se há possibilidade de racionalização de recursos dentro de uma estrutura judiciária já estabelecida. Existe muita tecnologia a respeito da prática da mediação,

\footnotetext{
13 Art. 166. A conciliação e a mediação são informadas pelos princípios da independência, da imparcialidade, da autonomia da vontade, da confidencialidade, da oralidade, da informalidade e da decisão informada. $\S 4^{\circ} \mathrm{A}$ mediação e a conciliação serão regidas conforme a livre autonomia dos interessados, inclusive no que diz respeito à definição das regras procedimentais. In: BRASIL. Lei $\mathrm{n}^{\circ}$ 13.105, de 16 de março de 2015. Código de Processo Civil. Diário Oficial da União. Brasília, Disponível em: <http://www.planalto.gov.br/ccivil_03/_Ato2015-2018/2015/Lei/L13105.htm>. Acesso em: 20 jun. 2015.

${ }^{14}$ Art. 165. Os tribunais criarão centros judiciários de solução consensual de conflitos, responsáveis pela realização de sessões e audiências de conciliação e mediação e pelo desenvolvimento de programas destinados a auxiliar, orientar e estimular a autocomposição. In: BRASIL. Lei $n^{\circ} 13.105$, de 16 de março de 2015. Código de Processo Civil. Diário Oficial da União. Brasília, Disponível em: <http://www.planalto.gov.br/ccivil_03/_Ato2015-2018/2015/Lei/L13105.htm>. Acesso em: 20 jun. 2015.

15 TARTUCE, Fernanda. Mediação no novo CPC: questionamentos reflexivos. 2013. Disponível em: <http://www.fernandatartuce.com.br/site/aulas/doc_view/339-mediacao-no-novo-cpc-tartuce.html> . Acesso em: 18 jul. 2015. p. 9.

${ }^{16}$ Artigo 169: Ressalvada a hipótese do art. 167 , $\$ 6^{\circ}$, o conciliador e o mediador receberão pelo seu trabalho remuneração prevista em tabela fixada pelo tribunal, conforme parâmetros estabelecidos pelo Conselho Nacional de Justiça. In: BRASIL. Lei $n^{\circ}$ 13.105, de 16 de março de 2015. Código de Processo Civil. Brasília, Disponível em: <http://www.planalto.gov.br/ccivil_03/_Ato20152018/2015/Lei/L13105.htm>. Acesso em: 20 jun. 2015.
} 
para se otimizar seus resultados ${ }^{17}$, todavia, qualquer investimento a mais em estrutura gerará custos a serem pagos pelo contribuinte.

Ao se racionalizar o uso da estrutura já existente nas serventias, a imagem a ser passada é a de cooperação e participação de todos os envolvidos, de forma ativa, na resolução das controvérsias. A intenção é produzir a sensação de que o local é mais humanitário em comparação à "frieza" jurisdicional do Fórum, afastando a ideia de hierarquia do juiz pela presença do mediador voluntário à causa.

Outro ponto controverso do NCPC diz respeito à possibilidade de escolha do mediador pelas partes. Segundo o parágrafo primeiro do artigo 165, os litigantes podem escolher, de comum acordo, o mediador, o qual pode estar ou não cadastrado no tribunal, lista que pode ser preenchida mediante concurso público. De maneira diferente, o artigo 25 da Lei de Mediação prevê que os mediadores não estão sujeitos à prévia aceitação das partes. A lei específica impõe o mediador judicial às partes, enquanto que o NCPC possibilita a liberdade de escolha. A interpretação principiológica mais adequada seria a de manter a livre escolha, conforme a liberdade procedimental e a autonomia, uma vez que tal tipo de institucionalização, se retirado esse direito de escolha das partes, prejudicaria o vínculo de confiança a ser formado.

A mediação pode ser aplicada a diversas áreas e segmentos específicos, tais como o direito societário, de consumo, negocial e comercial. A escolha do mediador pelas partes pode facilitar o diálogo, visto que podem eleger alguém que conheça os detalhes técnicos/tecnológicos/industriais da controvérsia e seja uma "autoridade" reconhecida e com legitimidade social na área.

Fiorelli ${ }^{18}$ aduz que o mediador, diferentemente dos magistrados e árbitros, não tem o poder de julgar o conflito. Sua atuação é ajudar os envolvidos a tomar uma decisão dialogada e de forma consciente, de responsabilidade de ambas as partes. ${ }^{19}$ Assim, a figura do mediador, por ser compreendida como a figura de um líder sem poder de decisão, não pode ter a mesma visão de impessoalidade profissional do magistrado. Se ambas as partes o enxergam o mediador como

\footnotetext{
${ }_{17}$ GAJARDONI, Fernando da Fonseca; ROMANO, Michel Betenjane; LUCHIARI, Valéria Feriolo Lagrasta. 0 Gerenciamento do Processo. In: WATANABE, Kazuo; LAGRASTA NETO, Caetano. (Coords.) Mediação e gerenciamento do processo: revolução na prestação jurisdicional: guia prático para a instalação do setor de conciliação e mediação. São Paulo: Ed. Atlas, 2007, p. 22.

${ }^{18}$ CAVALCANTE, Márcio André Lopes. Comentários à Lei 13.140/2015 (Lei da Mediação). Manaus: Dizer 0 Direito, 2015.

${ }^{19}$ FIORELLI, José Osmir; MALHADAS JUNIOR, Marcos Julio Olivé; MORAES, Daniel Lopes de. Psicologia na mediação: inovando a gestão de conflitos interpessoais e organizacionais. SP: Ltr, 2004. p. 52.
} 
ANÁLISE DA INSTITUCIONALIZAÇÃO DA MEDIAÇÃO A PARTIR DAS INOVAÇÕES DO NOVO CÓDIGO DE PROCESSO CIVIL (NCPC) E DA LEI N 13.140/2015 (LEI DA MEDIAÇÃO)

SERGIO RODRIGO MARTINEZ STEPHANIE GALHARDO SCHULZ

alguém que pode auxiliar efetivamente na resolução do conflito, essa legitimação social é importante a facilitar o sucesso do procedimento.

O impasse da possibilidade ou não de escolha dos mediadores ainda será alvo de discussão doutrinária e jurisprudencial pela colisão legal existente. Contudo, considerando que a Lei 13.140/2015 trata-se de lei específica, enquanto que o NCPC é norma geral, uma solução pela lógica da especialidade traria uma institucionalização com impacto negativo às amplas possibilidades atualmente à disposição da mediação. ${ }^{20}$

Outro ponto a ser analisado diz respeito às previsões dos parágrafos terceiro e quarto do artigo 167 do NCPC, que dispõem sobre as câmaras e os cadastros de mediadores. Em tais registros deverão constar dados de resultado de sua atuação, tais como o número de feitos em que participou e se obteve ou não "sucesso" na atividade, bem como que essas estatísticas comparativas serão divulgadas para a população e publicadas, ao menos, anualmente. ${ }^{21}$

Apesar da intenção positiva de se garantir transparência sobre resultados obtidos na utilização da mediação, cabe ressaltar que é pouco desejado, devido às peculiaridades da prática mediativa, que os resultados institucionalizados acarretem a criação de um ranking de mediadores. Isso porque o termo "sucesso", dentro da mediação, não é linear no tempo e difere-se radicalmente da concepção de sucesso no ganho ou na perda de uma causa, medida válida somente a processos, por estatísticas de produção de sentenças e realização de audiências (e processos findos). Nas mediações, por vez, só por se permitir o retorno do diálogo entre as partes no presente, mesmo sem a possibilidade imediata de acordo, há resultados de longo prazo, em termos de pacificação social, para além das "frias" planilhas de metas anuais:

Ao permitir a legitimação dos envolvidos no que diz respeito a suas necessidades e interesses, esse procedimento pode gerar um diálogo cooperativo e otimizar a

\begin{abstract}
${ }^{20}$ CAVALCANTE, Márcio André Lopes. Comentários à Lei 13.140/2015 (Lei da Mediação). Manaus: Dizer 0 Direito, 2015.

${ }^{21}$ Artigo 167, § 3을 Do credenciamento das câmaras e do cadastro de conciliadores e mediadores constarão todos os dados relevantes para a sua atuação, tais como o número de processos de que participou, o sucesso ou insucesso da atividade, a matéria sobre a qual versou a controvérsia, bem como outros dados que o tribunal julgar relevantes. In: BRASIL. Lei $n^{\circ}$ 13.105, de 16 de março de 2015. Código de Processo Civil. Diário Oficial da União. Brasília, Disponível em: <http://www.planalto.gov.br/ccivil_03/_Ato2015-2018/2015/Lei/L13105.htm>. Acesso em: 20 jun. 2015. $\S 4^{\circ}$ Os dados colhidos na forma do $\S 3^{\circ}$ serão classificados sistematicamente pelo tribunal, que os publicará, ao menos anualmente, para conhecimento da população e para fins estatísticos e de avaliação da conciliação, da mediação, das câmaras privadas de conciliação e de mediação, dos conciliadores e dos mediadores. In: BRASIL. Lei $\mathrm{n}^{\circ} 13.105$, de 16 de março de 2015. Código de Processo Civil. Diário Oficial da União. Brasília, Disponível em: <http://www.planalto.gov.br/ccivil_03/_Ato2015-
\end{abstract} 2018/2015/Lei/L13105.htm>. Acesso em: 20 jun. 2015. 
ANÁLISE DA INSTITUCIONALIZAÇÃO DA MEDIAÇÃO A PARTIR DAS INOVAÇÕES DO NOVO CÓDIGO DE PROCESSO CIVIL (NCPC) E DA LEI No 13.140/2015 (LEI DA MEDIAÇÃO)

qualidade da comunicação, a fim de garantir o equilíbrio das falas e do poder da interação. O objetivo é favorecer a construção de uma nova dinâmica cooperativa na direção de acordos, na medida do possível, satisfatórios para todos os envolvidos. Entretanto, mesmo sem resultar em acordo, uma mediação pode ser bem sucedida, bastando que tenha facilitado o diálogo entre as partes e despertado sua capacidade de se entenderem sozinhas. ${ }^{22}$

Em outro ponto, a Lei 13.140/2015 complementou a institucionalização do Novo Código de Processo Civil, ao estabelecer a regulamentação da mediação extrajudicial. Porém, ao estabelecer a ela prazos e penalidades, sua institucionalização foi além do esperado. Nesse sentido, cabe destacar a crítica a essas penalidades:

Ao deixar a mediação à sombra de um Tribunal ou punir as partes que resistem ao convite para mediar, fere-se a sua identidade, ora aproximando-a da adjudicação (processualização), ora confundindo-a com uma conciliação (patrimonialização). Em ambos os casos o resultado final fica aquém das expectativas. ${ }^{23}$

Aparentemente, essa regra da penalização já nasce enquanto “letra morta” na Lei da Mediação, especialmente no seu campo extrajudicial, quando são as partes, por sua própria autonomia e interesse privado, que a procuram, visando compor suas controvérsias ou obter auxílio ao diálogo, de maneira reservada. Vários são os casos em que psicólogos acabam, em terapia de casais ou de famílias, estabelecendo uma verdadeira mediação terapêutica, longe de advogados ou qualquer aparato jurisdicional. Qual o sentido de estabelecer uma punição ou prazos a serem cumpridos, quando são as partes que, por autonomia, farão essas escolhas livremente?

Daí que, nesses casos, quando a mediação transita enquanto negócio jurídico por autonomia privada das partes, que a institucionalização desse mecanismo passa a ser negativa e sem qualquer utilidade prática, com indevida presença no Estado a regular interesses privados e que só cabem às partes assim dispor. Outrossim, ao se falar novamente sobre o que se pretende ser, uma "mediação judicial institucionalizada”, deve ficar clara a cautela sobre os níveis de sua

\footnotetext{
${ }^{22}$ GONÇALVES, Fernando. Abertura do III Curso de Formação de Multiplicadores em Mediação e técnicas autocompositivas. Disponível em: <http://bdjur.stj.jus.br/jspui/bitstream/2011/29687/ Abertura_Ill\%20Curso_Forma\%C3\%A7\%C3\%A3o.doc.pdf> Acesso em: 10 jan. 2016. p. 03.

23 PAUMGARTTEN, Michele Pedrosa; PINHO, Humberto Dalla Bernardina de. Os efeitos colaterais da crescente tendência à judicialização da Mediação. Revista Eletrônica de Direito Processual: Periódico Semestral da Pós-Graduação Stricto Sensu em Direito Processual da UERJ, Rio de Janeiro, 2013.
} 
integração à estrutura do Poder Judiciário, que os autores denominam de "peso da intervenção estatal"24:

A onipresença da mediação nos Tribunais, nos códigos de processo, bem como obrigá-la é um contrassenso e a cautela nas expectativas que tratam a mediação como uma panaceia para os males dos sistemas de justiça é mandatória. 0 Poder Judiciário, por sua vez, deve ser aliado dos programas de mediação e não procurar absorvê-los. Se o acesso à justiça inclui o acesso a sistemas de ADR, é fundamental ter em mente os valores que fizeram a mediação, em particular, ser tão atraente para que não se torne simplesmente um processo privado se instalando num ambiente público, sendo consumido por regras e por uma concepção instrumentalista que vem a servir apenas à administração da justiça e não à garantia do efetivo acesso à justiça enquanto valor. ${ }^{25}$

O estímulo à maior efetividade da mediação não deve ocorrer mediante o sacrifício de preceitos fundamentais em face de uma burocratização estatal. Na visão de Paumgartten e Pinho, é necessário que o Poder Judiciário não se "aproprie" da mediação, porque a identidade do instituto não coaduna com o formalismo do âmbito judicial processual. Nesse sentido:

A mediação, como ética da alteridade, reivindica a recuperação do respeito e do reconhecimento da integridade e da totalidade de todos os espaços de privacidade do outro. Isto é, um respeito absoluto pelo espaço do outro, e uma ética que repudia o mínimo de movimento invasor. É radicalmente não invasora, não dominadora, não aceitando dominação sequer nos mínimos gestos. As pessoas estão tão impregnadas do espírito e da lógica da dominação que terminam, até sem saber, sendo absolutamente invasoras do espaço alheio. ${ }^{26}$

A mediação não irá servir de instrumento para resolver a morosidade processual e desafogar os tribunais pátrios. O objetivo da mediação é a pacificação dos conflitos por meio do diálogo e da retomada da comunicação entre os envolvidos e não dar agilidade à obtenção de soluções.

Nesse sentido pode ser verificado o exemplo de Portugal. Em terras lusitanas, a mediação é regulamentada no país desde 2001, atrelada à criação dos Julgados de Paz. Nos

\footnotetext{
24 PAUMGARTTEN, Michele Pedrosa; PINHO, Humberto Dalla Bernardina de. A institucionalização da mediação é a panaceia para a crise do acesso à justiça? 2012. Disponível em: <http://www.publicadireito.com.br/artigos/?cod=0fd4b8a8354a77a3>. Acesso em: 26 out. 2015, p. 26. 25 PAUMGARTTEN, Michele Pedrosa; PINHO, Humberto Dalla Bernardina de. A institucionalização da mediação é a panaceia para a crise do acesso à justiça? 2012. Disponível em: <http://www.publicadireito.com.br/artigos/?cod=0fd4b8a8354a77a3>. Acesso em: 26 out. 2015, p. 27. ${ }^{26}$ SPENGLER, Fabiana Marion; SPENGLER NETO, Theobaldo. Mediação enquanto política pública: a teoria, a prática e o projeto de lei. Santa Cruz do Sul, Edunisc, 2010. Disponível em: <http://www.unisc.br/portal/pt/editora/e-books/95/mediacao-enquanto-politica-publica-a-teoria-apratica-e-o-projeto-de-lei-.html>. Acesso em: 30 jul. 2015. p. 72.
} 
ANÁLISE DA INSTITUCIONALIZAÇÃO DA MEDIAÇÃO A PARTIR DAS INOVAÇÕES DO NOVO CÓDIGO DE PROCESSO CIVIL (NCPC) E DA LEI No 13.140/2015 (LEI DA MEDIAÇÃO)

SERGIO RODRIGO MARTINEZ STEPHANIE GALHARDO SCHULZ

Julgados de Paz, o papel da parte é ativo e cooperativo na resolução do conflito em questão. A mediação tem espaço preponderante dentro dos Julgados de Paz, porque ela afasta o extremo formalismo judicial e visa à pacificação do conflito, sem a presença de uma autoridade que se posicione em um plano hierárquico maior do que as partes em conflito ${ }^{27}$ :

A esta expansão deverá presidir uma lógica de complementaridade com a via judicial, sem cair no risco da inferenciação em relação aos tribunais judiciais. $\mathrm{Na}$ medida em que, transformar os julgados de paz em meros tribunais de pequenas causas cíveis seria desvirtuar os seus princípios enformadores e cercear a oferta de justiça. ${ }^{28}$

Spengler $^{29}$ ressalta que a mediação e o processo possuem modelos e princípios próprios e diferentes entre si. Enquanto a mediação caracteriza-se pela informalidade, oralidade e simplicidade, a prestação jurisdicional se dá por meio dos procedimentos e das sentenças de mérito.

A mediação, segundo Braga $\mathrm{Neto}^{30}$, detém caráter interdisciplinar, porque é aberta a vários ramos do conhecimento e não o Direito. Não há, portanto, a necessidade de a mediação ser realizada por sujeito com formação jurídica, porque, em muitos casos, profissionais de outras áreas seriam mais adequados para a prática, por possuírem habilidades de comunicação e experiência na criação do diálogo ${ }^{31}$ :

Havendo preponderância de aspectos interpessoais, o meio ideal de resolução da controvérsia é a Mediação, pois esse método privilegia a pacificação social e não necessariamente a conclusão de um acordo formal. Enquanto o conciliador busca a celebração do acordo, o mediador atua como facilitador do diálogo para que as partes possam expor as suas dificuldades num ambiente sigiloso e imparcial e,

27 VARGAS, Lúcia Dias. Julgados de Paz em Tempos de Crise. Disponível em: <https://www.inverbis.pt/2007-2011/images/stories/artigos/luciavargas_julgadospaztempocrise.pdf > Acesso em: 13 abr. 2017.

28 VARGAS, Lúcia Dias. Julgados de Paz em Tempos de Crise. Disponível em: <https://www.inverbis.pt/2007-2011/images/stories/artigos/luciavargas_julgadospaztempocrise.pdf > Acesso em: 13 abr. 2017.

29 SPENGLER, Fabiana Marion. Retalhos de Mediação. Porto Alegre: Essere Nel Mondo. $1^{\text {a }}$ ed. 2013. Disponível em: <http://www.esserenelmondo.com/pt/direito-o-principio-da-inafastabilidade-dajurisdicao-e-a-resolucao-de-conflitos-ebook62.php> Acesso em: 27 jul. 2015. p. 47.

${ }_{30}$ BRAGA NETO, Adolfo. Alguns Aspectos Relevantes sobre a Mediação de Conflitos. In: WATANABE, Kazuo; LAGRASTA NETO, Caetano. (Coords.) Mediação e gerenciamento do processo: revolução na prestação jurisdicional: guia prático para a instalação do setor de conciliação e mediação. São Paulo: Ed. Atlas, 2007. p. 68.

${ }^{31}$ SPENGLER, Fabiana Marion; SPENGLER NETO, Theobaldo. Mediação enquanto política pública: a teoria, a prática e o projeto de lei. Santa Cruz do Sul, Edunisc, 2010. Disponível em: <http://www.unisc.br/portal/pt/editora/e-books/95/mediacao-enquanto-politica-publica-a-teoria-apratica-e-o-projeto-de-lei-.html>. Acesso em: 30 jul. 2015. p. 73. 
ANÁLISE DA INSTITUCIONALIZAÇÃO DA MEDIAÇÃO A PARTIR DAS INOVAÇÕES DO NOVO CÓDIGO DE PROCESSO CIVIL (NCPC) E DA LEI No 13.140/2015 (LEI DA MEDIAÇÃO)

por isso, confiável. Assim, o objeto maior da mediação não é a rápida obtenção do acordo, mas a condução das partes a um estado de cooperação. 0 mediador aplica as técnicas da negociação para que as partes, que antes eram incapazes de negociar diretamente, acabem por o fazer através de um terceiro que conduz a discussão do problema[... $]^{32}$

Especialmente na mediação aplicada com frequência aos conflitos familiares, a presença do psicólogo é fundamental, uma vez que tais conflitos carregam grande carga emocional. São questões emocionalmente profundas que necessitam da preservação do relacionamento futuro entre as partes, especialmente quando há filhos menores envolvidos. ${ }^{33}$

Conforme frisa Kobayashi: "Será que estamos preparados para dar esse passo de maneira consciente, atendendo a todas as necessidades da mediação?" 34 Tudo parece depender do caminho que a criação dos CJSCC seguir. Se mais voltado ao que já existe em termos de mediação extrajudicial, aos moldes do que seguiram os Julgados de Paz portugueses, ou, a lógica judiciária formalista e burocratizante dominante no Brasil.

Em entrevista ao Portal Consultor Jurídico, Kazuo Watanabe afirmou que a morosidade processual brasileira não decorre de más legislações, mas de gerenciamento e, sobretudo, pela questão cultural. ${ }^{35} \mathrm{O}$ Brasil caracteriza-se pela cultura do litígio, que faz com que os cidadãos procurem, de forma predominante, o Poder Judiciário em detrimento de outras formas de resolução de conflitos. Assim, a mera institucionalização da mediação, dentro do Poder Judiciário, não será capaz, por si só, de alterar essa litigiosidade reinante no brasileiro, aparentemente cordial.

Nesse sentido, Paumgartten e Pinho ${ }^{36}$ criticam as legislações estrangeiras que preveem a realização obrigatória da mediação, tal qual a Lei Popular chinesa e afirmam que, embora essa

\footnotetext{
32 BRAGA NETO, Adolfo. Alguns Aspectos Relevantes sobre a Mediação de Conflitos. In: WATANABE, Kazuo; LAGRASTA NETO, Caetano. (Coords.) Mediação e gerenciamento do processo: revolução na prestação jurisdicional: guia prático para a instalação do setor de conciliação e mediação. São Paulo: Ed. Atlas, 2007. p. 69.

33 FIORELLI, José Osmir; MALHADAS JUNIOR, Marcos Julio Olivé; MORAES, Daniel Lopes de. Psicologia na mediação: inovando a gestão de conflitos interpessoais e organizacionais. SP: Ltr, 2004. p. 72.

${ }^{34}$ KOBAYASHI, Fernanda Mayumi. A mediação no novo CPC: estão todos preparados? 2015. Disponível em: <http://justificando.com/2015/05/25/a-mediacao-no-novo-cpc-estao-todos-preparados/> Acesso em: 01 nov. 2015.

${ }^{35}$ WATANABE, Kazuo. Sociedade não pode ser tão dependente do Estado para resolver conflitos. 2014. Disponível em: <http://www.conjur.com.br/2014-nov-09/entrevista-kazuo-watanabe-advogadodesembargador-aposentado-tj-sp> Acesso em: 01 nov. 2015.

${ }^{36}$ PAUMGARTTEN, Michele Pedrosa; PINHO, Humberto Dalla Bernardina de. A institucionalização da mediação é a panaceia para a crise do acesso à justiça? 2012. Disponível em: <http://www.publicadireito.com.br/artigos/?cod=0fd4b8a8354a77a3>. Acesso em: 26 out. 2015, p. 28.
} 
saída pareça atraente, compromete a identidade dessa via consensual, que é caracterizada pela voluntariedade.

Vale ressaltar que a finalidade maior da jurisdição não é a prolação de uma sentença, ou a resolução de uma questão jurídica, mas sim a pacificação social. A submissão de uma lide ao procedimento da mediação não significa, portanto, que o sujeito foi impedido de propor a sua demanda perante o Poder Judiciário. Até mesmo porque a chamada "obrigatoriedade da mediação", nos ordenamentos que a utilizam, é voltada apenas para o Poder Judiciário, que, nos casos em que for possível e recomendado, deverá sugeri-la às partes antes de prosseguir no exame jurídico da causa. Contudo, a mediação só se realizará de fato se ambas as partes estiverem de acordo com a sua instauração, até porque não faria sentido perder tempo com uma tentativa de busca de uma solução consensual quando uma das partes não demonstra interesse nela.

O NCPC evidencia a importância da mediação enquanto autocomposição, porém, sem retirar o foco do processo enquanto primazia processual de resolução de conflitos dentro do aparato estatal, tendência que se refletiu também na Lei de Mediação:

Art. $1^{\circ}$ Esta Lei dispõe sobre a mediação como meio de solução de controvérsias entre particulares e sobre a autocomposição de conflitos no âmbito da administração pública.

Parágrafo único. Considera-se mediação a atividade técnica exercida por terceiro imparcial sem poder decisório, que, escolhido ou aceito pelas partes, as auxilia e estimula a identificar ou desenvolver soluções consensuais para a controvérsia.

Logo, entender a mediação judicial enquanto saída à crise de acesso à Justiça não é de bom alvitre e sem efetividade a ser comprovada no tempo para afastamento da Cultura do Litígio. Por seu turno, há que se ficar atento e questionar o aumento do "inchaço" da administração da justiça já existente a gerar burocracia. ${ }^{37}$ Estabelecer um sistema de "mediação em série" que opere por uma lógica mecânica, formalista constitui em erro grave, devido à concepção dessa via consensual, em muito oposta ao apanágio judiciário:

A mediação é um trabalho artesanal. Cada caso é único. Demanda tempo, estudo, análise aprofundada das questões sob os mais diversos ângulos. O mediador deve se inserir no contexto emocional-psicológico do conflito. Deve

\footnotetext{
${ }^{37}$ RODRIGUES, Horácio Wanderlei; TRENTINI, Maria Alice. A Implementação da Mediação no Brasil: Uma Análise Crítica da Resolução CNJ 125/2010 e do PL N. ${ }^{\circ}$ 8.046/2010. I Seminário Internacional de Mediação de Conflitos e Justiça Restaurativa. Disponível em: <http://online.unisc.br/acadnet/anais/index.php/mediacao_e_jr/article/view/10857/1389>. Acesso em: 22 jul. 2015. p. 19.
} 
ANÁLISE DA INSTITUCIONALIZAÇÃO DA MEDIAÇÃO A PARTIR DAS INOVAÇÕES DO NOVO CÓDIGO DE PROCESSO CIVIL (NCPC) E DA LEI No 13.140/2015 (LEI DA MEDIAÇÃO)

buscar os interesses, por trás das posições externas assumidas, para que possa indicar às partes o possível caminho que elas tanto procuravam. ${ }^{38}$

Institucionalizar a mediação é uma saída interessante, do ponto de vista de reforçamento da prática mediativa, todavia, longe de promover algo novo, se colocada às sombras dos Tribunais. ${ }^{39}$ Para Pinho e Paumgartten, a presença excessiva da mediação em normas jurídicas é um paradoxo, uma espécie de "processo privado se instalando num ambiente público, sendo consumido por regras e por uma concepção instrumentalista que vem a servir apenas à administração da justiça" ${ }^{40}$ e não a pacificação social.

Porto e Neves ${ }^{41}$, em seu turno, frisam que para a mediação atingir os fins para os quais foi concebida, não é necessária extensa regulamentação, visto que seu papel vigora com bons resultados em âmbito extrajudicial. Conforme Fiorelli, Malhadas Junior e Moraes:

A mediação não foge a essa regra. Ela não se constitui em uma panaceia, isto é, um mecanismo mágico capaz de solucionar todos conflitos. Acreditar que ela substituirá o poder judiciário em sua concepção clássica, que ela desenvolverá uma nova sociedade, que os acordos celebrados por meio dela serão perfeitos é a ingenuidade ou empolgação trazida pela novidade. ${ }^{42}$

Segundo Veras e Fragale Filho ${ }^{43}$, a institucionalização da mediação, da forma como ocorrida, apesar de aparentar ser inovadora, obedece a regras muito semelhantes às judiciárias, o que prejudicará sua prática. Para esses autores supracitados, esse é o principal desafio da institucionalização da mediação no Brasil: permitir que haja a coexistência entre o método alternativo de solucionar conflitos e o sistema tradicional de resolver os conflitos, sem a absorção de um pelo outro. Nesse sentido:

\footnotetext{
${ }^{38}$ PINHO, Humberto Dalla Bernardina de. Os princípios e as garantias fundamentais no projeto de Código de Processo Civil: breves considerações acerca dos artigos $1^{\circ}$ a 12 do PLS 166/10. Revista Eletrônica de Direito Processual: Periódico Semestral da Pós-Graduação Stricto Sensu em Direito Processual da UERJ, Rio de Janeiro, 2011, p. 08.

39 PAUMGARTTEN, Michele Pedrosa; PINHO, Humberto Dalla Bernardina de. A institucionalização da mediação é a panaceia para a crise do acesso à justiça? 2012. Disponível em: <http://www.publicadireito.com.br/artigos/?cod=0fd4b8a8354a77a3>. Acesso em: 26 out. 2015, p. 209.

${ }^{40}$ Ibidem.

41 PORTO, Vanessa de Araújo; NEVES, Isabelli Cruz de Souza. Diálogos sobre a institucionalização da mediação de conflitos no Brasil. Disponível em: <http://www.publicadireito.com.br/artigos/?cod=e490b26afec38de1> Acesso em: 01 jan. 2016. p. 22.

42 FIORELLI, José Osmir; MALHADAS JUNIOR, Marcos Julio Olivé; MORAES, Daniel Lopes de. Psicologia na mediação: inovando a gestão de conflitos interpessoais e organizacionais. SP: Ltr, 2004. p. 74-75.

${ }^{43}$ VERAS, Cristiana Vianna. FRAGALE FILHO, Roberto. A judicialização da mediação no poder judiciário brasileiro: mais do mesmo nas disputas familiares? Disponível em: <https://eces.revues.org/1717\#tocto1n4> Acesso em: 18 dez. 2015.
} 
De certa forma, quando o Estado se apropria do instituto da mediação para dirimir conflitos, a partir de uma mediação realizada por serventuários do poder judiciário, mais uma vez chama para si a responsabilidade (e o monopólio) de resolver os conflitos sociais. Não deixa de ser uma forma de controle social e também de manutenção de um poder institucional com pretensão de moldar e organizar o conflito social. ${ }^{44}$

Em suma, a institucionalização da mediação trará vantagens e desvantagens. Entretanto, permanecerá essa cultura da jurisdicionalização do conflito, ao se alocar a mediação enquanto instrumento judicial. A prática mediativa pode sim ser importante aliada na busca da pacificação social, escopo maior da Jurisdição e do acesso à Justiça, se for compreendida dentro da ótica da complementaridade, de soma, e não da adjudicação, porque essa última opção pode acarretar na inversão dos valores do que, de fato, significa mediar.

\section{CONCLUSÃO}

Apesar da concepção da mediação ser antiga, a tentativa de institucionalização brasileira remonta ao advento da Resolução $n^{\circ} 125$ do CNJ, de 2010, que previu uma série de mecanismos para regulamentação dessa via consensual. Muitos desses mecanismos influenciaram significativamente a redação dos dispositivos do NCPC e da Lei 13.140/2015 e clarificaram a preocupação em melhorar a entrega da efetiva prestação jurisdicional.

Nesse contexto, a publicação do NCPC e da Lei 13.140/2015 reflete tendências tradicionais na forma de se compreender e solucionar os litígios no Brasil. $\mathrm{O}$ aspecto positivo dessas produções legislativas é a preocupação do modo como as demandas serão solucionadas, ao incentivar o uso da mediação, extrajudicial e judicial. Há o interesse de fomentar a utilização de métodos consensuais devido aos inúmeros benefícios que acarretam à ordem jurídica e social.

É evidente a importância que a mediação alcançou dentro do NCPC, o termo é claramente tratado várias vezes, em detrimento da inexistência do vocábulo no antigo códex processual. No entanto, há dispositivos que suscitam debates acerca do papel da mediação nas novas produções legiferantes, tais como a utilização do vocábulo "estimular" em relação ao fomento da mediação; a previsão dos CJSC funcionarem dentro da estrutura do Poder Judiciário; do conflito entre o NCPC e a Lei 13.140/2015, bem como no que tange a possibilidade de as

\footnotetext{
${ }^{44}$ VERAS, Cristiana Vianna. FRAGALE FILHO, Roberto. A judicialização da mediação no poder judiciário brasileiro: mais do mesmo nas disputas familiares? Disponível em: <https://eces.revues.org/1717\#tocto1n4> Acesso em: 18 dez. 2015.
} 
ISSN 1981-3694

(DOI): $10.5902 / 1981369424178$

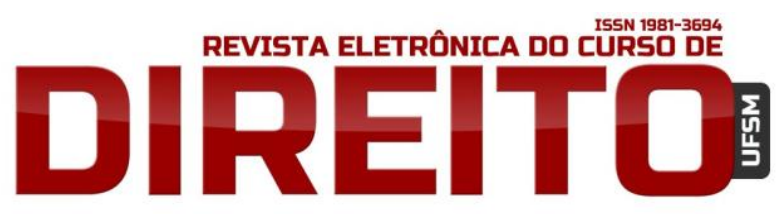

ANÁLISE DA INSTITUCIONALIZAÇÃO DA MEDIAÇÃO A PARTIR DAS INOVAÇÕES DO NOVO CÓDIGO DE PROCESSO CIVIL (NCPC) E DA LEI N 13.140/2015 (LEI DA MEDIAÇÃO)

SERGIO RODRIGO MARTINEZ STEPHANIE GALHARDo SCHULZ

partes escolherem os mediadores e das sanções para quem não comparecer à sessão de mediação extrajudicial.

Inúmeros juristas se posicionam contra a institucionalização excessiva, por acreditarem que desvirtuaria a identidade do que de fato significa mediar. A forma como a mediação está prevista no NCPC e na Lei 13.140/2015 é vista com cautela, porque a burocratização excessiva do método alternativo de resolução de conflitos seria indesejada.

Cumpre destacar que o que torna a Mediação atraente em relação aos demais métodos reside justamente na sua ética do diálogo pacificador, em sua lógica voluntária e cooperativa para o afastamento da Cultura do Litígio e em benefícios de longo prazo à ordem jurídica. A judicialização plena da mediação não é benéfica porque a sua regência pela ótica formalista não irá garantir o acesso à justiça. A mediação não pode ser compreendida como o remédio para sanar os males da Crise da Justiça, sob o risco de ir contra a sua essência e afastá-la ao plano secundário de ser mais um mecanismo de administração tradicional da justiça, quando, na verdade, funciona bem ao manter-se de forma independente.

A lógica judiciária analisa estatisticamente a resolução dos conflitos, por meio do número de demandas findas, sentenças prolatadas, acordos celebrados. A mediação, por ir ao âmago dos conflitos jurídicos, preconiza que inúmeros conflitos podem ser solucionados de formas menos gravosas e a serviço do acordo e pacificação satisfatória entre as partes. A filosofia mediativa prioriza o diálogo porque tem a premissa de que nem todos os conflitos podem ser resolvidos de forma imediata, que a Cultura da Paz só será realidade por meio de mudanças graduais na forma de comunicação das adversidades sociais.

Nesse contexto, há a importância de se construir um sistema de coexistência entre a administração tradicional da justiça e a mediação, sem que haja a apropriação de um pelo outro, sob risco de inviabilizar a ética de alteridade característica do procedimento mediativo e, sobretudo, na perda da oportunidade de empoderar os cidadãos e de transformar o papel exercido pelas partes na solução dos conflitos jurídicos.

\section{REFERÊNCIAS}

BARBADO, Michelle Tonon (Org.). Reflexões sobre a institucionalização da mediação no direito positivo brasileiro. Disponível em: <http://www.arcos.org.br/livros/estudos-de-arbitragemmediacao-e-negociacao vol3/parte-ii-doutrina-parte-especial/reflexoes-sobre-ainstitucionalizacao-da mediacao-no-direito-positivo-brasileiro/> Acesso em: 01 nov. 2015. 
ANÁLISE DA INSTITUCIONALIZAÇÃO DA MEDIAÇÃO A PARTIR DAS INOVAÇÕES DO NOVO CÓDIGO DE PROCESSO CIVIL (NCPC) E DA LEI N 13.140/2015 (LEI DA MEDIAÇÃO)

SERGIO RODRIGO MARTINEZ STEPHANIE GALHARDO SCHULZ

BARBOSA, Rui. Oração aos moços. 5. ed. São Paulo, Casa Rui Barbosa, 1999. Disponível em: <http://www.casaruibarbosa.gov.br/dados/DOC/artigos/rui_barbosa/FCRB_RuiBarbosa_Oracao_ aos_mocos.pdf> Acesso em: 11 nov. 2015.

BAVARESCO, Andrea Serra. Mediação: uma alternativa à jurisdição? Dissertação (Programa de pós-graduação). Universidade Federal do Rio Grande do Sul. Porto Alegre, 2006. Disponível em: <https://www.lume.ufrgs.br/bitstream/handle/10183/13178/000582339.pdf?sequence=1> Acesso em: 02 jul. 2015.

BOLZAM, A.; DOS SANTOS, R. A mediação e a conciliação no novo Código de Processo Civil. Cadernos de Direito. 2015. Disponível em: <https: //www. metodista.br/revistas/revistasunimep/index.php/direito/article/view/2406/1459>. Acesso em: 29 jul. 2015.

BRAGA NETO, Adolfo. Alguns Aspectos Relevantes sobre a Mediação de Conflitos. In: WATANABE, Kazuo; LAGRASTA NETO, Caetano. (Coords.) Mediação e gerenciamento do processo: revolução na prestação jurisdicional: guia prático para a instalação do setor de conciliação e mediação. São Paulo: Ed. Atlas, 2007.

BRASIL. Lei $n^{\circ}$ 13.105, de 16 de março de 2015. Código de Processo Civil. Diário Oficial da União. Brasília, Disponível em: <http://www.planalto.gov.br/ccivil_03/_Ato2015-

2018/2015/Lei/L13105.htm>. Acesso em: 20 jun. 2015.

BRASIL. Lei no 13140, de 26 de junho de 2015. Lei da Mediação. Diário Oficial da União. Brasília, Disponível em: <http://www.planalto.gov.br/ccivil_03/_Ato2015-

2018/2015/Lei/L13140.htm>. Acesso em: 08 set. 2015.

CAVALCANTE, Márcio André Lopes. Comentários à Lei 13.140/2015 (Lei da Mediação). Manaus: Dizer O Direito, 2015.

CINTRA, Antônio Carlos de Araújo; GRINOVER, Ada Pellegrini; DINAMARCO, Cândido Rangel. Teoria Geral do Processo. 25. ed. São Paulo: Malheiros, 2009.

CONSELHO DA JUSTIÇA FEDERAL. Entrevista com Kazuo Watanabe. Disponível em: <http://www.cjf.jus.br/noticias-do-cjf/2014/novembro/professor-da-usp-fala-sobre-mediacaoe-arbitragem-em-seminario-no-cjf> Acesso em: 10 out. 2015.

CONSELHO NACIONAL DE JUSTIÇA. Resolução n. ${ }^{\circ} 125$, de 29 de novembro de 2010. Dispõe sobre a Política Judiciária Nacional de tratamento adequado dos conflitos de interesses no âmbito do Poder Judiciário e dá outras providências. Disponível em:

<http://www.cnj.jus.br/atos-administrativos/atos-da-presidencia/323-resolucoes/12243resolucao-no-125-de-29-de-novembro-de-2010> Acesso em: 18 jul. 2015.

DEMARCHI, Juliana. Mediação: Proposta de Implementação no Processo Civil Brasileiro. 2007. 308 f. Tese (Doutorado) - Curso de Direito, Departamento de Departamento de Direito Processual Civil, Faculdade de Direito da Universidade de São Paulo, São Paulo, 2007, Disponível em: http: / / www.teses.usp.br/teses/disponiveis/2/2137/tde-01042008-132345/pt-br.php> Acesso em: 10 set. 2015. 
ANÁLISE DA INSTITUCIONALIZAÇÃO DA MEDIAÇÃO A PARTIR DAS INOVAÇÕES DO NOVO CÓDIGO DE PROCESSO CIVIL (NCPC) E DA LEI N 13.140/2015 (LEI DA MEDIAÇÃO)

SERGIO RODRIGO MARTINEZ STEPHANIE GALHARDO SCHULZ

DEMARCHI, Juliana. Técnicas de Conciliação e Mediação. In: WATANABE, Kazuo; LAGRASTA NETO, Caetano. (Coords.) Mediação e gerenciamento do processo: revolução na prestação jurisdicional: guia prático para a instalação do setor de conciliação e mediação. São Paulo: Ed. Atlas, 2007.

FIORELLI, José Osmir; MALHADAS JUNIOR, Marcos Julio Olivé; MORAES, Daniel Lopes de. Psicologia na mediação: inovando a gestão de conflitos interpessoais e organizacionais. São Paulo: Ltr, 2004.

GAJARDONI, Fernando da Fonseca; ROMANO, Michel Betenjane; LUCHIARI, Valéria Feriolo Lagrasta. O Gerenciamento do Processo. In: WATANABE, Kazuo; LAGRASTA NETO, Caetano. (Coords.) Mediação e gerenciamento do processo: revolução na prestação jurisdicional: guia prático para a instalação do setor de conciliação e mediação. São Paulo: Ed. Atlas, 2007.

GONÇALVES, Fernando. Abertura do III Curso de Formação de Multiplicadores em Mediação e técnicas autocompositivas. Disponível em:

<http://bdjur.stj.jus.br/jspui/bitstream/2011/29687/Abertura_III\%20Curso_Forma\%C3\%A7\%C3\%A 3o.doc.pdf> Acesso em: 10 jan. 2016.

GRINOVER, Ada Pellegrini. A inafastabilidade do controle jurisdicional e uma nova modalidade de autotutela: (parágrafos únicos dos artigos 249 e 251 do Código Civil). Revista Brasileira de Direito Constitucional - Rbdc, São Paulo, n. 10, dez. 2007. Disponível em:

<http://bdjur.stj.jus.br/xmlui/bitstream/handle/2011/26126/inafastabilidade_controle_jurisdic ional_nova.pdf?sequence=1> Acesso em: 20 ago. 2015.

GRINOVER, Ada Pellegrini. Os Fundamentos da Justiça Conciliativa. In: WATANABE, Kazuo; LAGRASTA NETO, Caetano. (Coords.) Mediação e gerenciamento do processo: revolução na prestação jurisdicional: guia prático para a instalação do setor de conciliação e mediação. São Paulo: Ed. Atlas, 2007.

KOBAYASHI, Fernanda Mayumi. A mediação no novo CPC: estão todos preparados? 2015. Disponível em: <http://justificando.com/2015/05/25/a-mediacao-no-novo-cpc-estao-todospreparados/> Acesso em: 01 nov. 2015.

KRIVIS, Jeffrey. End of the Cold War: The Marriage of Mediation and the Court System. Disponível em: <http://mediate.com/articles/krivis7.cfm\#bio> Acesso em: 02 out 2015.

LAGRASTA NETO, Caetano. Mediação, conciliação e suas aplicações pelo Tribunal de Justiça de São Paulo. In: GRINOVER, Ada Pellegrini; WATANABE, Kazuo. (Coords.) Mediação e gerenciamento do processo: revolução na prestação jurisdicional: guia prático para a instalação do setor de conciliação e mediação. São Paulo: Ed. Atlas, 2007.

LUCHIARI, Valéria Ferioli Lagrasta. Mediação judicial: análise da realidade brasileira origem e evolução até a Resolução n. 125, do Conselho Nacional de Justiça. In: GRINOVER, Ada Pellegrini; WATANABE, Kazuo (Coord.). Rio de Janeiro: Forense, 2012. (Coleção ADRS).

MENDES, Aluísio G. de Castro. Princípio da Inafastabilidade da Prestação Jurisdicional à Luz do Acesso à Justiça. In: TORRES, Ricardo Lobo; KATAOKA, Eduardo Takemi; GALDINO, Flavio. Dicionário de Princípios Jurídicos. Rio de Janeiro: Elsevier, 2011. 
MORI, Amaury Haruo. Princípios gerais aplicáveis aos processos de mediação e de conciliação. Disponível em:

<http://www.trt9.jus.br/internet_base/arquivo_download.do?evento=Baixar\&idArquivoAnexado $\mathrm{PlC}=1608509>$ Acesso em: 14 out. 2015.

NETO, Adolfo Braga. Alguns Aspectos Relevantes sobre a Mediação de Conflitos. In: WATANABE, Kazuo; LAGRASTA NETO, Caetano. (Coords.) Mediação e gerenciamento do processo: revolução na prestação jurisdicional: guia prático para a instalação do setor de conciliação e mediação.

São Paulo: Ed. Atlas, 2007.

NETO, Caetano Lagrasta. Mediação, conciliação e suas aplicações pelo Tribunal de Justiça de São Paulo. In: GRINOVER, Ada Pellegrini; WATANABE Kazuo (Coords.) Mediação e gerenciamento do processo: revolução na prestação jurisdicional: guia prático para a instalação do setor de conciliação e mediação. São Paulo: Ed. Atlas, 2007.

PAUMGARTTEN, Michele Pedrosa; PINHO, Humberto Dalla Bernardina de. A institucionalização da mediação é a panaceia para a crise do acesso à justiça? 2012. Disponível em:

<http://www. publicadireito.com.br/artigos/?cod=0fd4b8a8354a77a3> Acesso em: 26 out. 2015.

PAUMGARTTEN, Michele Pedrosa; PINHO, Humberto Dalla Bernardina de. Os efeitos colaterais da crescente tendência à judicialização da Mediação. Revista Eletrônica de Direito Processual: Periódico Semestral da Pós-Graduação Stricto Sensu em Direito Processual da UERJ, Rio de Janeiro, 2013.

PINHO, Humberto Dalla Bernardina de. Os princípios e as garantias fundamentais no projeto de Código de Processo Civil: breves considerações acerca dos artigos $1^{\circ}$ a 12 do PLS 166/10. Revista Eletrônica de Direito Processual: Periódico Semestral da Pós-Graduação Stricto Sensu em Direito Processual da UERJ, Rio de Janeiro, 2011.

PIQUET, Hélène. A mediação popular na China: acesso à justiça ou harmonia imposta? In: Revista Meritum. Belo Horizonte. Vol. 7. 2012.

PORTO, Vanessa de Araújo; NEVES, Isabelli Cruz de Souza. Diálogos sobre a institucionalização da mediação de conflitos no Brasil. Disponível em:

<http://www. publicadireito.com.br/artigos/?cod=e490b26afec38de1> Acesso em: 01 jan. 2016.

RODRIGUES, Horácio Wanderlei; TRENTINI, Maria Alice. A Implementação da Mediação no Brasil: Uma Análise Crítica da Resolução CNJ 125/2010 e do PL N. ${ }^{\circ}$ 8.046/2010. In: I Seminário Internacional de Mediação de Conflitos e Justiça Restaurativa. Disponível em: <http://online.unisc.br/acadnet/anais/index.php/mediacao_e_jr/article/view/10857/1389> Acesso em: 22 jul. 2015.

SALES, Lília Maia de Morais; ANDRADE, Mariana Dionísio de. A mediação de conflitos como efetivo contributo ao Poder Judiciário. Revista de Informação Legislativa, Brasília, 2011. Disponível em:

<http://www2.senado.leg.br/bdsf/bitstream/handle/id/242928/000936208.pdf?sequence=3> Acesso em: 01 ago. 2015. 
ANÁLISE DA INSTITUCIONALIZAÇÃO DA MEDIAÇÃO A PARTIR DAS INOVAÇÕES DO NOVO CÓDIGO DE PROCESSO CIVIL (NCPC) E DA LEI N 13.140/2015 (LEI DA MEDIAÇÃO)

SERGIO RODRIGO MARTINEZ STEPHANIE GALHARDO SCHULZ

SANTANNA, Ana Carolina Squadri. O Princípio da Inafastabilidade da Jurisdição e a Resolução de Conflitos. 1 ed. Rio Grande do Sul: Editora Essere Nel Mondo, 2015. Disponível em: <http://www.esserenelmondo.com/pt/direito-o-principio-da-inafastabilidade-da-jurisdicao-e-aresolucao-de-conflitos-ebook62.php> Acesso em: 27 jul. 2015.

SILVA, De Plácido e. Vocabulário Jurídico. 28. ed. Rio de Janeiro: Forense, 2010.

SPENGLER, Fabiana Marion. Retalhos de Mediação. Porto Alegre: Essere Nel Mondo. $1^{\text {a }}$ ed. 2013. Disponível em: <http://www.esserenelmondo.com/pt/direito-o-principio-da-inafastabilidadeda-jurisdicao-e-a-resolucao-de-conflitos-ebook62.php> Acesso em: 27 jul. 2015.

SPENGLER, Fabiana Marion; SPENGLER NETO, Theobaldo. Mediação enquanto política pública: a teoria, a prática e o projeto de lei. Santa Cruz do Sul, Edunisc, 2010. Disponível em: <http://www.unisc.br/portal/pt/editora/e-books/95/mediacao-enquanto-politica-publica-ateoria-a-pratica-e-o-projeto-de-lei-.html> Acesso em: 30 jul. 2015.

TARTUCE, Fernanda. Mediação no novo CPC: questionamentos reflexivos. 2013. Disponível em: <http://www.fernandatartuce.com.br/site/aulas/doc_view/339-mediacao-no-novo-cpctartuce.html> Acesso em: 18 jul. 2015.

VARGAS, Lúcia Dias. Julgados de Paz em Tempos de Crise. Disponível em: <https://www.inverbis.pt/2007-

2011/images/stories/artigos/luciavargas_julgadospaztempocrise.pdf> Acesso em: 13 abr. 2017.

VERAS, Cristiana Vianna; FRAGALE FILHO, Roberto. A judicialização da mediação no poder judiciário brasileiro: mais do mesmo nas disputas familiares? Disponível em: <https://eces.revues.org/1717\#tocto1n4> Acesso em: 18 dez. 2015.

WAMBIER, Luiz Rodrigues; TALAMINI, Eduardo. Curso Avançado De Processo Civil: Teoria Geral do Processo e Processo de Conhecimento, v.1. 10. ed. São Paulo: Revista do Tribunais, 2008.

WATANABE, Kazuo. Sociedade não pode ser tão dependente do Estado para resolver conflitos. 2014. Disponível em: <http://www.conjur.com.br/2014-nov-09/entrevista-kazuo-watanabeadvogado-desembargador-aposentado-tj-sp> Acesso em: 01 nov. 2015.

WATANABE, Kazuo. Modalidade de mediação. In: Mediação: Um Projeto Inovador. José Delgado et. al. Série Cadernos do Conselho da Justiça Federal. Brasília: Centro de Estudos Judiciários, 2003. v. 22. Disponível em: <http://daleth.cjf.jus.br/revista/seriecadernos/vol22/artigo04.pdf> Acesso em: 30 jul. 2015.

Recebido em: 28/09/2016 / Revisões requeridas em: 16/11/2016 / Aprovado em: 21/11/2016 